\title{
SELF-REGULATED LEARNING SISWA SMK MUHAMMADIYAH DI KOTA YOGYAKARTA: KEDUA ORANG TUA BERPENGARUHKAN?
}

\author{
Wahyu Nanda Eka Saputra \\ Irvan Budhi Handaka \\ Universitas Ahmad Dahlan \\ E-mail: wahyu.saputra@bk.uad.ac.id \\ Dita Kurnia Sari \\ Universitas Islam Negeri Sunan Ampel Surabaya \\ E-mail: ditakurniasari1988@gmail.com
}

\begin{abstract}
Abstrak
Tujuan penelitian ini untuk mengidentifikasi perbedaan tingkat self-regulated learning berdasarkan siswa yang tinggal bersama kedua orang tuanya dengan siswa yang tinggal tidak bersama kedua orang tuanya. Penelitian ini melibatkan jumlah sampel sebanyak 415 siswa SMK Muhammadiyah di Kota Yogyakarta yang diambil menggunakan teknik stratified random sampling. Sampel terdiri dari 143 siswa tidak tinggal bersama orang tuanya dan 272 siswa tinggal bersama kedua orang tuanya. Tingkat self-regulated learning diukur menggunakan skala self-regulated learning. Teknik analisis data yang digunakan adalah Independent Sample T-Test. Hasil penelitian menunjukkan bahwa tidak ada perbedaan rata-rata skor selfregulated learning siswa SMK yang tinggal dengan kedua orang tuanya dengan siswa siswa yang tidak tinggal dengan kedua orang tuanya. Hasil penelitian ini seyogyanya menjadi dasar bagi konselor untuk meningkatkan self-regulated learning siswa dengan melibatkan unsur internal pada diri siswa buka unsur eksternal pada diri siswa seperti peran orang tua.
\end{abstract}

Kata Kunci: self-regulated learning, hasil belajar, orang tua.

\begin{abstract}
The purpose of this study is to identify differences in levels of self-regulated learning based on students who live with their parents with students who live not with their parents. This study involved a sample of 415 students of Muhammadiyah Vocational Schools in Yogyakarta City who were taken using the stratified random sampling technique. The sample consisted of 143 students not living with their parents and 272 students living with their parents. The level of self-regulated learning is measured using a selfregulated learning scale. The data analysis technique used was the Independent Sample T-Test. The results showed that there was no difference in the average self-regulated learning scores of vocational students who lived with their parents with students who did not live with their parents. The results of this study should be the basis for counselors to improve student self-regulated learning by involving the internal elements in the students to open the external elements in students such as the role of parents.
\end{abstract}

Keywords: self-regulated learning, learning outcome, parent.

\section{PENDAHULUAN}

Prestasi dalam belajar menjadi satu komponen penting bagi siswa. Pencapaian prestasi belajar yang optimal menjadi indikator bahwa siswa berhasil dalam belajarnya. Siswa yang memperoleh prestasi belajar yang maksimal juga berdampak signifikan terhadap kepuasan siswa dalam menikmati proses belajar yang dilakukan siswa. Kepuasan yang dirasakan oleh siswa dalam proses pembelajaran menjadi pendorong bagi siswa dalam melakukan pembelajaran yang lebih dalam untuk memperoleh preatasi akademik yang maksimal (Carrillode-la-Peña \& Perez, 2012).

Self-regulated learning menjadi salah satu keterampilan yang perlu dimiliki oleh siswa agar mereka mampu mendapatkan prestasi belajar yang maksimal. Berbagai hasil penelitian menunjukkan bahwa selfregulated learning perlu menjadi keterampilan yang dioptimalkan siswa karena berkontribusi signifikan terhadap prestasi belajar (Broadbent \& Poon, 2015; Caprara et al., 2008; Kosnin, 2007; Latipah, 2010; Zimmerman, 1990, 2013; Zimmerman \& Schunk, 1989, 1989). Hasil-hasil penelitian tersebut menjadi dasar bagi 
para pemangku kepentingan untuk melihat pentingnya variabel self-regulated learning bagi siswa agar mereka memiliki masa depan yang baik sesuai dengan harapan dari siswa.

Self-regulated learning digambarkan melalui tingkatan atau derajat yang meliputi keaktifan baik secara metakognisi, motivasi, maupun perilaku siswa di dalam proses belajar (Zimmerman \& Schunk, 1989). Pernyataan tersebut memiliki pengertian bahwa self-regulated learning menjadi usaha aktif dan mandiri siswa dalam proses belajarnya dengan cara memantau, mengatur dan mengontol kognisi, motivasi, dan perilaku, yang diorientasikan atau diarahkan pada tujuan belajar. Dimensi self-regulated learning mendorong seseorang dalam mengembangkan kemampuan mengatur diri dalam belajarnya secara baik.

Terdapat empat asumsi umum mengenai self-regulated learning. Pertama, asumsi aktif dan konstruktif. Siswa sebagai partisipan yang aktif konstruktif dalam proses belajar, baik itu aktif mengkonstruk pemahaman dan tujuan, maupun strategi dari informasi yang tersedia di lingkungan dan pikirannya sendiri. Kedua, potensi untuk mengontrol. Siswa sanggup memonitor, mengontrol, meregulasi aspek tertentu dari kognitif, motivasi dan perilaku sesuai karakteristik lingkungan jika memungkinkan. Ketiga, asumsi tujuan, kriteria, atau standar. Asumsi tersebut digunakan untuk menilai apakah proses harus dilanjutkan, bila perlu ketika beberapa kriteria atau standar berubah. Keempat, aktivitas regulasi diri merupakan penengah (mediator) antara personal dan karakteristik konteks dan prestasi atau performa yang sesungguhnya (Wolters, Pintrich, \& Karabenick, 2005).

Berdasarkan pemaparan di atas, self-regulated learning menjadi variabel yang penting bagi siswa dalam membantu mereka mencapai prestasi akademik yang diharapkan. Namun, permasalahan tentang self-regulated learning masih menjadi masalah bagi siswa dan perlu dientaskan. Hasil penelitian pada siswa SMA akselerasi di kota Malang menunjukkan bahwa 54,2\% siswa memiliki self-regulated learning rendah, yang menggambarkan bahwa siswa tidak memiliki perencanaan dan pengaturan waktu dalam pembelajaran, tidak memiliki strategi pembelajaran, rendahnya motivasi, dan kurang memanfaatkan sumber-sumber yang ada (Savira \& Suharsono, 2013). Penelitian lain juga menunjukkan bahwa pelajar yang bekerja memiliki tingkat selfregulated learning yang kurang baik jika dibandingkan dengan pelajar yang juga bekerja dalam memenuhi kebutuhan hidupnya (Daulay \& Rola, 2009).

Masalah terkait self-regulated learning salah satunya diprediksi oleh pengaruh dan peran dari kedua orang tua. Hasil penelitian menunjukkan bahwa dukungan sosial keluarga turut memberikan sumbangan yang signifikan terhadap kemampuan siswa dalam self-regulated learning (Adicondro \& Purnamasari, 2012). Dukungan tersebut menjadi penting bagi siswa karena akan memberikan reinforcement bagi siswa dalam memaksimalkan selfregulated learning, terlerbih siswa mendapatkan kesuksesan belajar yang maksimal.

Penelitian ini bertujuan untuk mengidentifikasi perbedaan tingkat self-regulated learning siswa SMK Muhammadiyah di Kota Yogyakarta berdasarkan siswa yang tinggal bersama kedua orang tuanya dengan siswa yang tidak tinggal bersama kedua orang tuanya. Hasil penelitian ini akan memberikan rekomendasi bagi konselor di sekolah dalam upayanya membantu siswa meningkatkan self-regulated learning. Sehingga siswa nantinya akan mendapatkan hasil belajar atau prestasi akademik yang maksimal.

\section{METODE}

Rancangan penelitian ini adalah penelitian komparatif. Penelitian ini bertujuan untuk membandingkan perbedaan tingkat self-regulated learning siswa SMK Muhammadiyah di Kota Yogyakarta yang tinggal bersama kedua orang tuanya dengan siswa yang tidak tinggal bersama kedua orang tuanya. Populasi dalam penelitian ini adalah seluruh siswa kelas XI SMK Muhammadiyah Kota Yogyakarta dan sampel dalam penelitian ini sebanyak 415 siswa yang diambil secara stratified random sampling. Sampel terdiri dari 143 siswa tidak tinggal bersama orang tuanya dan 272 siswa tinggal bersama kedua orang tuanya.

Teknik pengumpulan data yang digunakan dalam penelitian ini adalah skala self-regulated learning yang terdiri dari 43 item pernyataan. Teknik analisis data yang digunakan dalam penelitian ini adalah Independent Sample T-Test. Hasil dari analisis menggunakan Independent Sample T-Test akan diperoleh perbedaan tingkat self-regulated learning siswa SMK Muhammadiyah Kota Yogyakarta yang tinggal dengan kedua orang tua dengan yang tidak tinggal bersama kedua orang tua. Analisis Independent Sample T-Test menggunakan bantuan program komputer yaitu SPSS.

\section{HASIL DAN PEMBAHASAN}

Hasil penelitian ini menunjukkan bahwa terdapat perbedaan yang signifikan self-regulated learning siswa SMK di Yogyakarta antara siswa yang diasuh oleh kedua orang tuanya dengan siswa yang tidak diasuh oleh kedua orang tuanya. Hasil penelitian tersebut dianalisis dengan menggunakan uji independent sample t-test. Uji beda tersebut menggunakan dua asumsi yang telah teruji, yaitu data harus berdistribusi normal dan data sejenis atau homogen. 
Uji normalitas menggunakan Shapiro-Wilk dengan bantuan SPSS. Output dari hasil pengujian normalitas adalah sebagai berikut:

Tabel 1. Uji Normalitas

Tests of Normality

\begin{tabular}{llccc}
\hline \multirow{2}{*}{ Tinggal Dengan } & \multicolumn{3}{c}{ Shapiro-Wilk } \\
\cline { 2 - 5 } & Statistic & df & Sig. \\
\hline SkorS & $\begin{array}{l}\text { Tinggal tidak dengan } \\
\text { RL }\end{array}$ & .990 & 143 & .435 \\
& $\begin{array}{l}\text { Tinggal dengan orang } \\
\text { tua }\end{array}$ & .993 & 272 & .237 \\
\hline
\end{tabular}

*. This is a lower bound of the true significance.

\section{Lilliefors Significance Correction}

Berdasarkan tabel Tests of Normality, diperoleh nilai signifikasi untuk siswa yang tinggal dengan kedua orang tuanya sebesar 0,435 dan nilai signifikansi siswa yang tinggal dengan kedua orang tua sebesar 0,237. Karena nilai kedua kelompok siswa lebih besar dari 0,05, maka dapat disimpulkan bahwa data skor tingkat self-regulated learning berdistribusi normal.

Uji homogenitas menggunakan Oneway ANOVA dengan bantuan SPSS. Output dari hasil pengujian homogenitas adalah sebagai berikut:

Tabel 2. Uji Homogenitas

Test of Homogeneity of Variances

Skor SRL

\begin{tabular}{|c|c|c|c|}
\hline Levene Statistic & df1 & df2 & Sig. \\
\hline .296 & 1 & 413 & .586 \\
\hline
\end{tabular}

Berdasarkan output Test of Homogeneity of Variances, diketahui bahwa nilai signifikansi variabel skor tingkat self-regulated learning berdasarkan variabel siswa tinggal dengan kedua orang tua dan siswa tinggal tidak dengan orang tua adalah sebesar 0,296 dan nilai signifikansi tersebut lebih dari 0,05 . Artinya data variabel skor tingkat self-regulated learning berdasarkan variabel siswa tinggal dengan kedua orang tua dan siswa tinggal tidak dengan orang tua mempunyai varian yang sama atau homogen.

Sehingga, dua asumsi uji independent sample t-test telah terpenuhi dan dapat dilaksanakan tahap pengujian hipotesis. Hasil output analisis uji independent sample ttest dengan bantuan SPSS adalah sebagai berikut:

Tabel 3. Uji Independent Sample T-Test Independent Samples Test

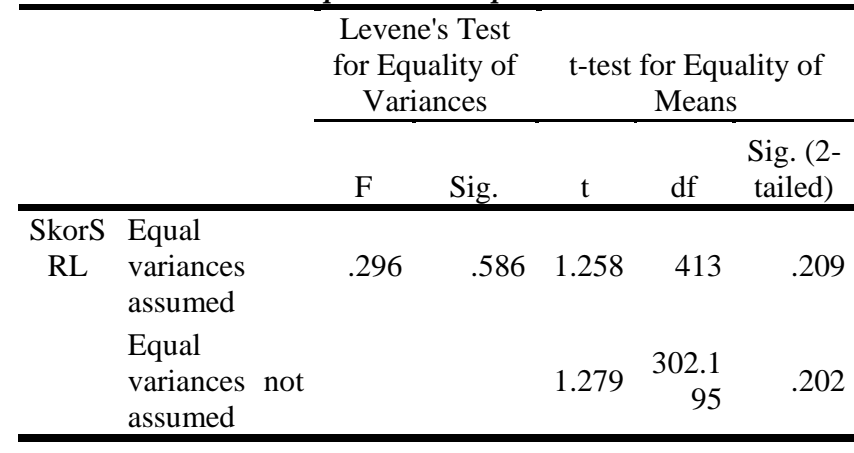

Berdasarkan output independent sample t-test dengan bantuan SPSS tersebut diketahui bahwa nilai signifikansi sebesar 0,209 yang mana nilai signifikansi tersebut lebih besar dari 0,05. Artinya tidak ada perbedaan rata-rata skor self-regulated learning siswa SMK yang tinggal dengan kedua orang tuanya dengan siswa siswa yang tidak tinggal dengan kedua orang tuanya.

Temuan dari penelitian ini adalah tidak terdapat perbedaan yang signifikan tingkat self-regulated learning siswa yang tinggal bersama kedua orang tuanya dengan siswa yang tidak tinggal dengan kedua orang tuanya. Dengan bahasa lain, keberadaan orang tua tidak memiliki dampak pada self-regulated learning siswa. Temuan ini menjadi kajian baru bagi para pemangku kepentingan dalam membantu siswa mengembangkan self-regulated learning. Khususnya konselor memiliki program bimbingan dan konseling yang berpihak pada siswa dan berorientasi pada unsur dari dalam diri siswa untuk pengembangan self-regulated learning.

Hasil penelitian ini berbeda dengan penelitian sebelumnya yang pernah dilakukan. Terdapat penelitian yang menyebutkan siswa yang mendapat dukungan sosial keluarga, memiliki kemampuan self-regulated learning yang lebih baik (Adicondro \& Purnamasari, 2012). Ini terjadi karena siswa yang tinggal dengan orang tuanya, orang tua memberikan banyak dukungan bagi anaknya agar mendapatkan pencapaian prestasi akademik yang maksimal. Dukungan tersebut menjadi pemacu siswa untuk dapat memunculkan self-regulated learning yang dapat menganytarkannya mencapai prestasi maksimal.

Penelitian di Cina juga menunjukkan bahwa gaya pengasuhan orang tua memberikan dampak yang signifikan terhadap self-regulated learning siswa (Huang \& Prochner, 2003). Gaya pengasuhan otoritatif secara signifikan berkaitan dengan self-regulated learning siswa, sedangkan gaya orangtua otoriter tidak berpengaruh terhadap self-regulated learning siswa. Hasil penelitian ini juga menunjukkan bahwa gaya pengasuhan permisif dapat menunjukkan sedikit pengaruh, tetapi tidak signifikan, terhadap self-regulated learning siswa dan gaya pengasuhan pelatihan dapat menunjukkan sedikit pengaruh, tetapi tidak signifikan, terhadap self-regulated learning siswa.

Hasil penelitian lain juga menunjukkan bahwa dukungan sosial orang tua memiliki hubungan yang positif dengan kemandirian belajar siswa (Rambe, 2010). Hal tersebut memiliki makna bahwa semakin tinggi dukungan sosial orang tua, semakin tinggi pula tingkat kemandirian belajar yang ditunjukkan oleh siswa. Sebaliknya, semakin rendah dukungan sosial orang tua, semakin rendah pula tingkat kemandirian belajar siswa.

Terdapat pula penelitian yang menyebutkan bahwa dukungan yang diberikan oleh orang tua memiliki 
pengaruh signifikan terhadap manajemen diri siswa SMK dalam mempersiapkan kerja (Baiti \& Munadi, 2014). Penelitian tersebut tidak spresifik pada self-regulated learning tetapi prinsipnya sama, yaitu bagaimana kemampuan siswa memanajemen dirinya ketika dihadapkan pada situasi tertentu. Dukungan ini penting bagi siswa karena akan memberikan penguatan pada diri siswa untuk berbuat lebih dalam melakukan aktualisasi diri.

Akan tetapi zaman sekarang mengalami pergeseran luar biasa. Orang tua zaman sekarang memiliki kecenderungan untuk "membiarkan" anak tanpa pengawasan. Sehingga berbagai masalah anak berada di luar jangkauan orang tua. Yang sering terjadi adalah orang tua baru mengetahui kejelasan masalah anaknya ketika sudah timbul sebuah kasus tertentu. Sebagai contoh, orang tua mengetahui anaknya sering membolos ketika orang tua dipanggil untuk datang pada konselor di sekolah dan menceritakan bahwa anaknya melakukan berbagai perilaku yang tidak bertanggung jawab di sekolah.

Kegagalan orang tua dalam memberikan peran pada anaknya dalam hal akademik salah satunya juga tidak bisanya orang tua melatihkan rasa tanggung jawab pada diri siswa. Padahal orang tua perlu mengasuh anak dan melatihnya untuk dapat bertanggung jawab terhadap apa yang dimilikinya (Gordon, 1999). Hal ini berakibat pada tidak munculnya tanggung jawab pada diri siswa untuk dapat belajar mandiri yang akan mengantarkan mereka pada kesuksesan akademiknya.

Hal ini berkebalikan dengan yang seharusnya terjadi, yaitu keberhasilan anak tergantung pada bagaimana usaha orang tua mencapai keberhasilan dalam mengasuh (Graha, 2013). Perhatian orang tua perlu selalu muncul untuk anak-anak mereka ketika mereka sekolah (Bangun, 2008). Ahli lain menyebutkan bahwa keterlibatan orang tua dalam kegiatan anak akan memberikan efek berbeda (Finn, 1998). Jika orang tua mampu berperan sesuai dengan porsinya untuk mengasuh dan memberikan dukungan pada anaknya, maka akan memberikan dorongan pada anak untuk mencapai harapan dari anak dan orang tua dari anak itu sendiri. Dalam hal penelitian ini adalah keberhasilan siswa mencapai prestasi akademik melalui optimalisasi self-regulated learning.

Orang tua seharusnya berperan dalam menunjang keberhasilan belajar anak-anak mereka, termasuk mendukung pengembangan self-regulated learning untuk mencapai prestasi akademik yang maksimal (Fan \& Chen, 2001; Stewart, 2008). Tanggung jawab orang tua ini dapat diwujudkan dengan membimbing kelangsungan anak dalam belajar secara mandiri di rumah sesuai dengan program yang telah dipelajari anak-anak di sekolah. Membimbing anak-anak belajar di rumah dapat dilakukan dengan mengawasi dan membantu pengaturan tugas sekolah serta menyelesaikan instrumen dan infrastruktur anak belajar (Umar, 2015). Dan peran seperti ini tidak banyak muncul pada diri orang tua siswa.

\section{PENUTUP}

Hasil penelitian menunjukkan bahwa tidak ada perbedaan yang signifikan tingkat self-regulated learning siswa yang tinggal bersama kedua orang tuanya dengan siswa yang tidak tinggal dengan orang tuanya. Hal yang menjadi salah satu penyebabkan adalah pergeseran peran orang tua sekarang yang kurang memberikan dukungan maksimal bagi anaknya untuk mengembangkan diri dalam bidang akademiknya, dalam hal ini adalah self-regulated learning. Temuan penelitian ini merekomendasikan kepada praktisi di lapangan untuk dapat melibatkan orang tua untuk berpartisipasi aktif dan memberikan dukungan psikologis bagi siswa upaya mereka mengembangkan selfregulated learning. Peneliti selanjutnya, seyogyanya memperdalam penelitian dengan mengidentifikasi model dukungan atau peran orang tua yang cocok untuk membantu anaknya meningkatkan self-regulated learning.

\section{DAFTAR PUSTAKA}

Adicondro, N., \& Purnamasari, A. (2012). Efikasi diri, dukungan sosial keluarga dan self regulated learning pada siswa kelas VIII. HUMANITAS: Indonesian Psychological Journal, 8(1), 17-27.

Baiti, A. A., \& Munadi, S. (2014). Pengaruh Pengalaman Praktik, Prestasi Belajar Dasar Kejuruan dan Dukungan Orang Tua Terhadap Kesiapan Kerja Siswa SMK. Jurnal Pendidikan Vokasi, 4(2).

Bangun, D. (2008). Hubungan persepsi siswa tentang perhatian orang tua, kelengkapan fasilitas belajar, dan penggunaan waktu belajar di rumah dengan prestasi belajar ekonomi. Jurnal Ekonomi \& Pendidikan, 5(1).

Broadbent, J., \& Poon, W. L. (2015). Self-regulated learning strategies \& academic achievement in online higher education learning environments: A systematic review. The Internet and Higher Education, 27, 1-13.

Caprara, G. V., Fida, R., Vecchione, M., Del Bove, G., Vecchio, G. M., Barbaranelli, C., \& Bandura, A. (2008). Longitudinal analysis of the role of perceived self-efficacy for self-regulated learning in academic continuance and achievement. Journal of Educational Psychology, 100(3), 525.

Carrillo-de-la-Peña, M. T., \& Perez, J. (2012). Continuous assessment improved academic achievement and satisfaction of psychology 
students in Spain. Teaching of Psychology, 39(1), 45-47.

Daulay, S. F., \& Rola, F. (2009). Perbedaan self regulated learning antara mahasiswa yang bekerja dan yang tidak bekerja. Fakultas Psikologi. Universitas Sumatera Utara.

Fan, X., \& Chen, M. (2001). Parental involvement and students' academic achievement: A metaanalysis. Educational Psychology Review, 13(1), $1-22$.

Finn, J. D. (1998). Parental engagement that makes a difference. Educational Leadership, 55(8), 2024.

Gordon, T. (1999). Menjadi orang tua efektif: petunjuk terbaru mendidik anak yang bertanggung jawab. PT Gramedia Pustaka Utama.

Graha, C. (2013). Keberhasilan anak tergantung orang tua. Elex Media Komputindo.

Huang, J., \& Prochner, L. (2003). Chinese parenting styles and children's self-regulated learning. Journal of Research in Childhood Education, 18(3), 227-238.

Kosnin, A. M. (2007). Self-regulated learning and academic achievement in Malaysian undergraduates. International Education Journal, 8(1), 221-228.

Latipah, E. (2010). Strategi self regulated learning dan prestasi belajar: kajian meta analisis. Jurnal Psikologi, 37(1), 110-129.

Rambe, A. R. R. (2010). Korelasi Antara Dukungan Sosial Orang Tua dan Self-Directed Learning pada Siswa SMA. Jurnal Psikologi, 37(2), 216223.

Savira, F., \& Suharsono, Y. (2013). Self-Regulated Learning (SRL) dengan Prokrastnasi Akademik pada Siswa Akselerasi. Jurnal Ilmiah Psikologi Terapan, 1(1), 66-75.

Stewart, E. B. (2008). School structural characteristics, student effort, peer associations, and parental involvement: The influence of school-and individual-level factors on academic achievement. Education and Urban Society, 40(2), 179-204.

Umar, M. (2015). Peranan orang tua dalam peningkatan prestasi belajar anak. JURNAL EDUKASI: Jurnal Bimbingan Konseling, 1(1), 20-28.

Wolters, C. A., Pintrich, P. R., \& Karabenick, S. A. (2005). Assessing academic self-regulated learning. In What do children need to flourish? (pp. 251-270). Springer.

Zimmerman, B. J. (1990). Self-regulated learning and academic achievement: An overview. Educational Psychologist, 25(1), 3-17.
Zimmerman, B. J. (2013). Theories of self-regulated learning and academic achievement: An overview and analysis. In Self-regulated learning and academic achievement (pp. 1045). Routledge.

Zimmerman, B., \& Schunk, D. (1989). Self-regulated learning and academic: Theory, research, and practice. New York: Springer Verlag. 